MANY MEXICOS 



\section{LESLEY BYRD SIMPSON}
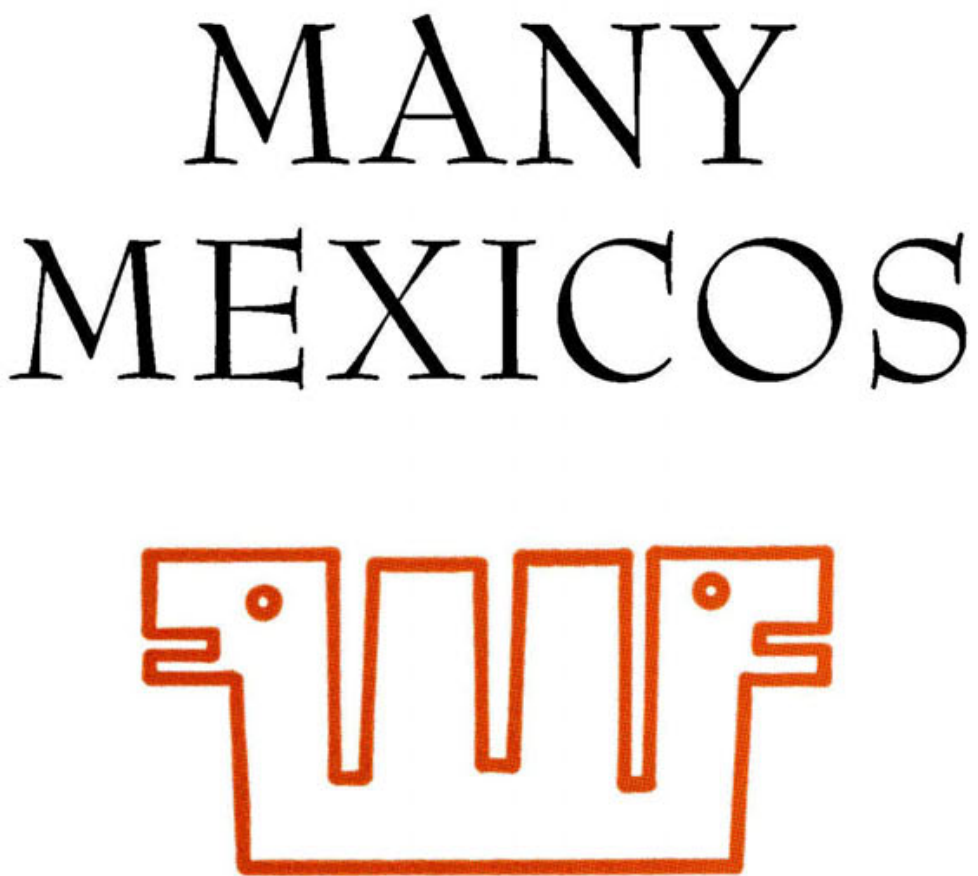

FOURTH EDITION REVISED

UNIVERSITY OF CALIFORNIA PRESS

BERKELEY AND LOS ANGELES

1966 
University of California Press

Berkeley and Los Angeles, California

\section{Cambridge University Press}

London, England

(C) $1941,1946,1952,1966$

by Lesley Byrd Simpson

Printed in the United States of America

Library of Congress Catalog Card Number: 66-19101 